\section{Revista de CIENCIAS AMBIENTALES Tropical Journal of Environmental Sciences}

Revista de Ciencias Ambientales (Trop J Environ Sci)

e-ISSN: 2215-3896

(Julio-Diciembre, 2021) . Vol 55(2): 71-90

DOI: https://doi.org/10.15359/rca.55-2.4

Open Access: www.revistas.una.ac.cr/ambientales e-mail: revista.ambientales@una.ac.cr Espinoza-Cisneros $\mathrm{E}$.

\title{
Percepciones sobre calidad del agua fluvial en administradores de unidades productivas de la cuenca del río Savegre, Costa Rica
}

\author{
Fluvial water quality perceptions in productive unit land managers of the \\ Savegre river watershed, Costa Rica
}

Édgar Espinoza-Cisneros ${ }^{1}$

[Recibido: 27 de mayo 2020, Aceptado: 28 de enero 2021, Corregido: 17 de febrero 2021, Publicado: 1 de julio 2021]

\section{Resumen}

[Introducción] En las ciencias de la sostenibilidad se reconoce, cada vez más, la importancia de entender las cogniciones y su rol en las decisiones ambientales. En conjunto con avances en teorizaciones sobre las cogniciones en general y las percepciones en particular, los análisis de las cogniciones ambientales en contextos particulares son imprescindibles para procesos efectivos de planificación ambiental. [Objetivo] En este artículo se examinan las percepciones ambientales de 109 administradores de unidades productivas en 15 comunidades de la cuenca del río Savegre, Costa Rica, en torno a la calidad del agua fluvial y sus amenazas asociadas. [Metodología] Las percepciones se capturaron a través de encuestas en persona y se analizaron con pruebas estadísticas no-paramétricas y técnicas de ranking. [Resultados] Las percepciones ambientales varían significativamente entre sectores de la cuenca, rangos de distancia al río, tipos de actividad productiva primaria, y niveles de educación formal. Además, la cobertura boscosa y los regímenes de protección ambiental se perciben como factores favorecedores de la calidad del agua fluvial, mientras que los factores desfavorecedores y amenazas prioritarias se relacionan casi en su totalidad con actividades productivas en la cuenca, especialmente la expansión de las fronteras agrícolas y ganaderas, la acuicultura y pesca destructiva, y la contaminación por agroquímicos. [Conclusiones] Se concluye que, en esta cuenca, las percepciones ambientales en torno a la calidad del agua fluvial están determinadas en gran medida por factores geográficos y contextuales, y que los administradores, a su vez, muestran patrones perceptivos donde se reconoce el impacto ecológico de las mismas actividades productivas que se han desarrollado en la cuenca en las últimas décadas.

Palabras clave: Cogniciones ambientales; cuenca hidrográfica; manejo de la tierra; paisaje rural; Reserva de la Biosfera Savegre.

\section{Abstract}

[Introduction] The importance of understanding environmental cognitions for effective environmental management is increasingly recognized within sustainability science. Along with advancements in theorizations about cognitions in general and perceptions in particular, analyses of environmental cognitions in specific contexts are indispensable for effective environmental planning processes. [Objective] In this article, environmental perceptions of fluvial water quality and its associated threats are examined for 109 land managers from 15

1 Docente e investigador de la Escuela de Geografía, Universidad de Costa Rica, Costa Rica; edgar.espinoza@ucr.ac.cr, https://orcid. org/0000-0002-1018-3440

\begin{tabular}{|c|c|}
\hline 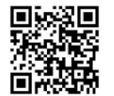 & (cc) $(9)$ \\
\hline
\end{tabular}
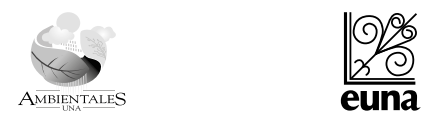


\section{Revista de CIENCIAS AMBIENTALES Tropical Journal of Environmental Sciences}

Revista de Ciencias Ambientales (Trop J Environ Sci)

e-ISSN: 2215-3896

(Julio-Diciembre, 2021) . Vol 55(2): 71-90

DOI: https://doi.org/10.15359/rca.55-2.4

Open Access: www.revistas.una.ac.cr/ambientales e-mail: revista.ambientales@una.ac.cr Espinoza-Cisneros E.

communities in the Savegre river watershed in Costa Rica. [Methodology] Perceptions were captured through face-to-face surveys and analyzed through non-parametric statistical tests and ranking techniques. [Results] Environmental perceptions vary significantly among watershed sectors, ranges of distances to the river, types of primary productive activities, and formal education levels. Moreover, forest cover and environmental protection regimes are perceived as key factors favoring fluvial water quality, while the disfavoring factors and priority threats were almost entirely related with productive activities within the watershed, especially the expansion of the agricultural and cattle frontiers, aquaculture and destructive fishing, and agrochemical pollution. [Conclusions] It is concluded that, in this watershed, environmental perceptions about fluvial water quality are determined in large part by geographical and contextual factors, and that land managers show perceptual patterns suggesting recognition of ecological impacts of the same productive activities that have been taking place in the watershed for the last decades.

Keywords: environmental cognitions; land management; rural landscape; Savegre Biosphere Reserve; watershed.

\section{Introducción}

Panoramas globales de crecientes retos ambientales han demandado abordajes más exhaustivos en estudios sobre las relaciones ser humano-medio ambiente. Marcos analíticos basados en teorías de sistemas y complejidad, por ejemplo, han resaltado la plétora de factores involucrados en estas relaciones, así como sus intrincadas dinámicas espacio-temporales. Estudios sobre las cogniciones y su rol en las decisiones ambientales han adquirido especial prominencia en los últimos años en campos disciplinarios que abordan las relaciones sociedad-naturaleza (Jacobs et al., 2016). Si bien estos componentes cognitivos han sido tradicionalmente relegados en investigaciones ambientales (Jones et al., 2016), crecientemente reciben mayor atención no solo en investigación, sino también en mecanismos para la toma de decisiones y políticas públicas, bajo la consigna de que, con la finalidad de atender muchos de los problemas socioambientales, es imperativo entender a fondo los factores cognitivos que subyacen las decisiones humanas.

De manera simplificada, las cogniciones ambientales fungen como intermediarios entre acciones (conductas) y el ambiente (Figura 1) (Meyfroidt, 2013). Si bien en esta relación también influyen factores exógenos (marcos normativos, dinámicas de mercado, acceso a tecnologías e infraestructura, etc.), las cogniciones subyacen las acciones ambientales, y es a través de estas que el agente evalúa y ejecuta las trayectorias de acción más viables según su esquema cognitivo (Gifford y Nilsson, 2014).

\begin{tabular}{|c|c|c|c|c|}
\hline 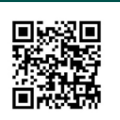 & (c) (i) (5)(2) & 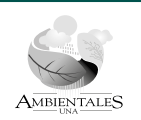 & $\frac{O \%}{2 \%}$ & 72 \\
\hline
\end{tabular}




\section{Revista de CIENCIAS AMBIENTALES Tropical Journal of Environmental Sciences}

Revista de Ciencias Ambientales (Trop J Environ Sci)

e-ISSN: 2215-3896

(Julio-Diciembre, 2021) . Vol 55(2): 71-90 DOI: https://doi.org/10.15359/rca.55-2.4 Open Access: www.revistas.una.ac.cr/ambientales e-mail: revista.ambientales@una.ac.cr Espinoza-Cisneros E.

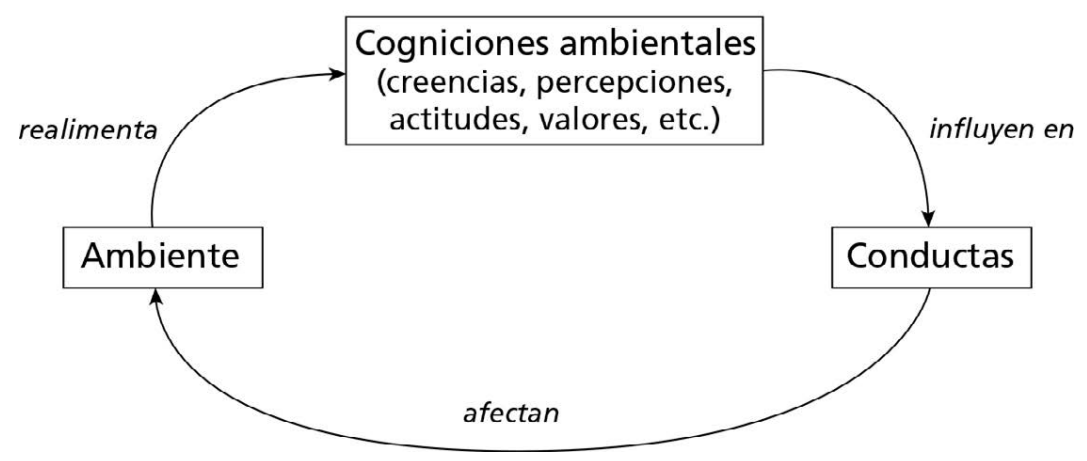

Figura 1. Diagrama que ilustra, de manera simplificada, el rol mediador de las cogniciones en las relaciones entre conductas y ambiente. Adaptado de Meyfroidt (2013).

Figure 1. Diagram illustrating, in a simplified manner, the mediating role of cognitions in behavior-environment relations. Adapted from Meyfroidt (2013).

Si bien campos como la psicología ambiental se remontan a la década de los cincuenta, en las últimas décadas se le ha dado una mayor atención a la relación entre cogniciones y medio ambiente, no solo en trabajos empíricos, sino también en el diseño de marcos analítico-conceptuales y metodológicos (Chan et al., 2016; Clayton y Saunders, 2012; Jacobs et al., 2016; Jones et al., 2016). Esto ha causado una mayor fertilización entre campos disciplinarios, principalmente la psicología, sociología, geografía y economía, entre otros. Estas colaboraciones multidisciplinarias han derivado en teorizaciones sobre la relación entre cogniciones ambientales y el contexto socioecológico bajo el cual se desarrollan. Aquí destacan, por ejemplo, las teorías sobre la cognición "encarnada" (embodied cognition), que apuntan a una visión donde "la cognición humana, incluyendo nuestro pensamiento más abstracto, está fundamentada en y estructurada por la realidad social y material en la cual se desarrolla y opera" (Hukkinen, 2012; p. 1. Traducción propia). La relación entre cogniciones ambientales y características sociodemográficas como edad, sexo, y nivel educativo ha sido también ampliamente tratada en diferentes contextos (Gifford y Nilsson, 2014). Estas relaciones se han expandido inclusive a otros factores más geográficos, como la distancia a cuerpos de agua u otros componentes o características del entorno espacial (Brody et al., 2004; Larson y Santelmann, 2007).

Sin embargo, existen aún importantes vacíos de investigación en al área de cogniciones ambientales (Clayton y Saunders, 2012; Verdugo et al., 2009). En particular, es escaso el conocimiento sobre los esquemas cognitivos de los principales tomadores de decisiones en unidades productivas, en especial aplicando abordajes multidisciplinarios para su estudio (Burton, 2004; Meyfroidt, 2013). Investigaciones en esta línea han utilizado diversos constructos cognitivos para, entre otras cosas, predecir la implementación de ciertas prácticas productivas (Price y Leviston, 2014), el estado de conservación de la biodiversidad (Fitzsimons y Wescott, 2007), así como para estudiar las dimensiones más representativas e identitarias asociadas a la implementación de las prácticas productivas (Burton y Wilson, 2006).

\begin{tabular}{|c|c|c|c|c|c|}
\hline 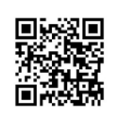 & (c) (1) (9) & $\underset{\text { AMBENTALES }}{\leftrightarrow}$ & $\frac{9 \%}{2 \%}$ & 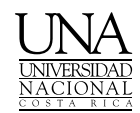 & 73 \\
\hline
\end{tabular}




\section{Revista de CIENCIAS AMBIENTALES Tropical Journal of Environmental Sciences}

Revista de Ciencias Ambientales (Trop J Environ Sci)

e-ISSN: 2215-3896

(Julio-Diciembre, 2021) . Vol 55(2): 71-90

DOI: https://doi.org/10.15359/rca.55-2.4

Open Access: www.revistas.una.ac.cr/ambientales e-mail: revista.ambientales@una.ac.cr Espinoza-Cisneros E.

Teorizaciones en las ciencias cognitivas y en la Geografía han tratado también la dualidad dinámica entre el paisaje y las percepciones ambientales. Nassauer (1995), por ejemplo, sintetiza bien lo anterior al sugerir cuatro principios sobre la relación entre cultura y paisaje. El primero de ellos es que la percepción, cognición y valoración humana del paisaje directamente afectan el paisaje y viceversa. El segundo indica que las convenciones culturales influyen fuertemente en los patrones espaciales del paisaje, tanto en paisajes habitados como en naturales. El tercero plantea que las concepciones culturales de la naturaleza difieren de las científicas sobre función ecológica; y el cuarto menciona que la apariencia de los paisajes comunica valores culturales. En efecto, el paisaje representa una impronta de las aspiraciones, valoraciones y atribuciones de significado, y constituye, en muchos sentidos, una manifestación espacial de estos factores cognitivos. Estas manifestaciones han sido ya por muchos años el objeto de estudio de disciplinas en las ciencias sociales que buscan entender esa relación entre cogniciones y la conformación de paisajes.

Un mejor entendimiento de la asociación entre cogniciones y decisiones de manejo de la tierra indudablemente contribuiría a la efectividad de estrategias $u$ otras intervenciones que busquen, por ejemplo, reconciliar la producción rural con la integridad funcional de los ecosistemas en paisajes productivos. Esta investigación aporta a ese entendimiento al examinar las percepciones ambientales de administradores de unidades productivas (de ahora en adelante UP) en torno a calidad del agua fluvial y sus amenazas asociadas en la cuenca del río Savegre, Costa Rica. Se enfatizaron los administradores a razón de ser los principales tomadores de decisiones en cuanto al manejo de las actividades productivas en cada UP.

\section{Metodología}

\subsection{Sitio de estudio}

La cuenca del río Savegre se ubica en la vertiente del Pacífico de Costa Rica, en la región del Pacífico Central (Figura 2). Esta se extiende por casi $600 \mathrm{~km}^{2}$ y comprende un rango altitudinal que va desde los casi 3500 metros a los 0 metros sobre el nivel del mar, en aproximadamente 42 kilómetros lineales. La cuenca incluye dos ríos principales: el División, por el este, y el Savegre, por el oeste, los cuales confluyen a 12 kilómetros lineales de la línea costera para luego continuar bajo el nombre de río Savegre. La red de drenaje de la cuenca es de tipo dendrítica, con una extensión de aproximadamente $3400 \mathrm{~km}$. El promedio de precipitación anual en la cuenca es de 4 $600 \mathrm{~mm}$ (MINAE-AECI, 2003).

Un rasgo distintivo de la cuenca es la gran diversidad de ecosistemas y microclimas que le confiere su gradiente altitudinal y que, a su vez, propicia una alta biodiversidad y endemismo (Acevedo et al., 2002; Rodríguez-Herrera, 2004). Por su relevancia para la conservación ecológica y el desarrollo de medios de vida rurales, en el año 2017 la UNESCO designa la Reserva de la Biósfera Savegre. En la cuenca se ubican áreas silvestres protegidas de gran importancia

\begin{tabular}{|c|c|c|c|c|c|}
\hline 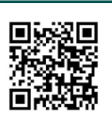 & (c) (i) $(0)$ & $\underset{\text { AMBENATIES }}{\infty}$ & $\frac{O \%}{2}$ & 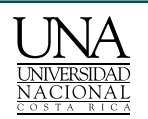 & 74 \\
\hline
\end{tabular}




\section{Revista de CIENCIAS AMBIENTALES Tropical Journal of Environmental Sciences}

Revista de Ciencias Ambientales (Trop J Environ Sci)

e-ISSN: 2215-3896

(Julio-Diciembre, 2021) . Vol 55(2): 71-90

DOI: https://doi.org/10.15359/rca.55-2.4

Open Access: www.revistas.una.ac.cr/ambientales e-mail: revista.ambientales@una.ac.cr Espinoza-Cisneros E.

nacional, entre las que destacan el Parque Nacional Los Quetzales en la cuenca alta, el Parque Nacional Manuel Antonio en la cuenca baja y la Reserva Forestal Los Santos en la cuenca media.

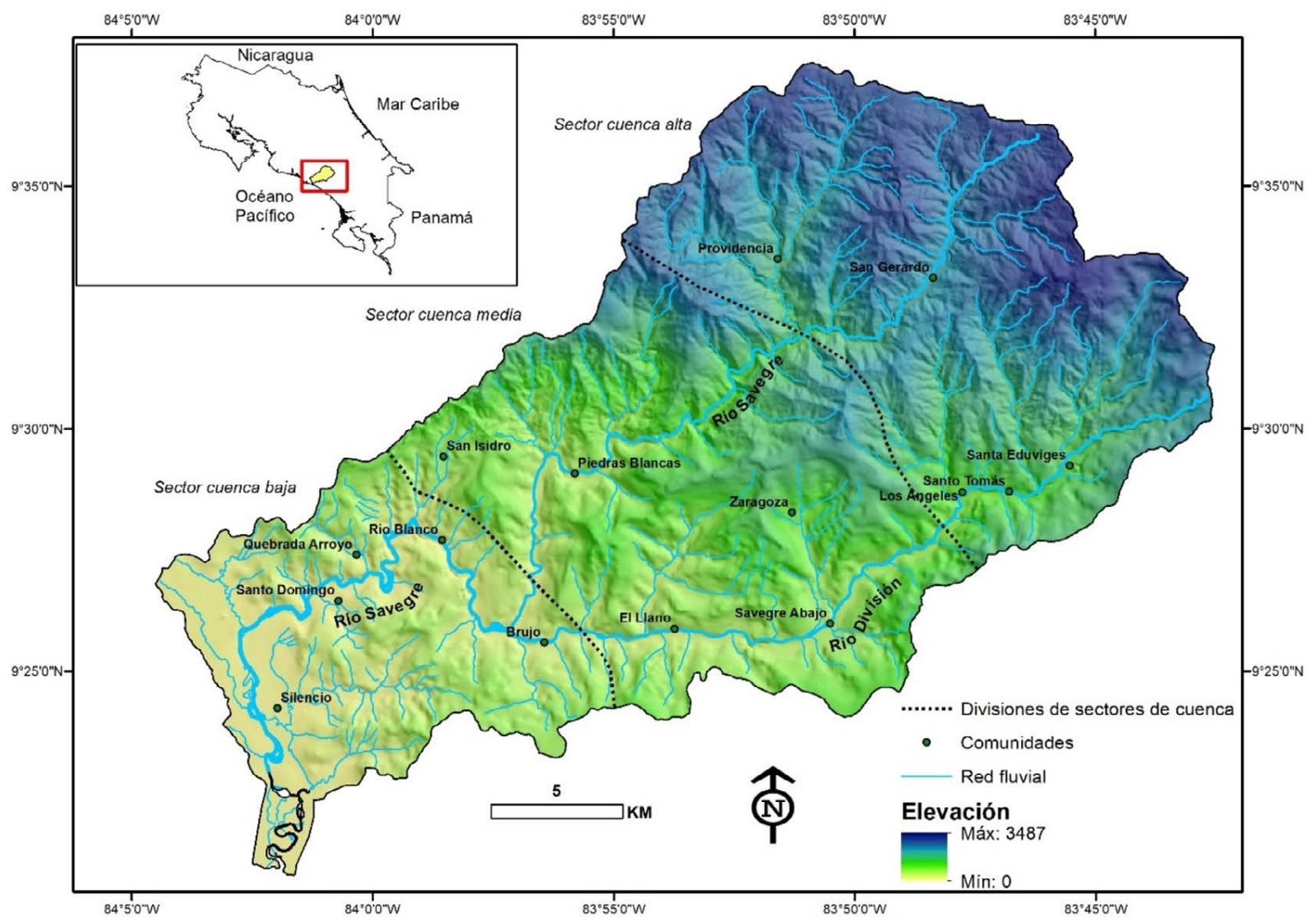

Figura 2. Mapa general de la cuenca del río Savegre.

Figure 2. General map of the Savegre river watershed.

La topografía abrupta y dificultades de acceso en la cuenca han indispuesto los asentamientos humanos. En efecto, la cuenca se caracteriza por su relativamente baja densidad de población $\left(\sim 40 \mathrm{p} / \mathrm{km}^{2}\right)$ comparado al promedio del país. La agricultura (café, palma africana, variedad de frutas), ganadería bovina y porcina, el turismo y la acuicultura están entre las principales actividades productivas en la cuenca. La mayoría de las UP son sistemas mixtos de baja y mediana escala que combinan, principalmente, agricultura y ganadería, $y$, en menor grado, turismo. En la cuenca alta destaca la actividad turística (principalmente de avistamiento de aves) mezclada con agricultura, específicamente el cultivo de frutas como aguacate, manzana, mora y melocotón. También se presenta, en menor grado, la acuicultura de truchas. En la cuenca alta también predomina el cultivo del café, particularmente en la subcuenca del río División. En la cuenca

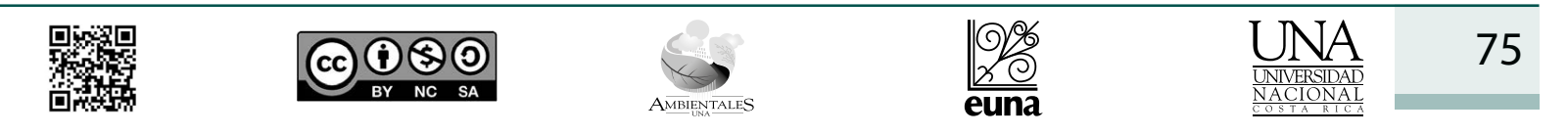




\section{Revista de CIENCIAS AMBIENTALES Tropical Journal of Environmental Sciences}

Revista de Ciencias Ambientales (Trop J Environ Sci)

e-ISSN: 2215-3896

(Julio-Diciembre, 2021) . Vol 55(2): 71-90

DOI: https://doi.org/10.15359/rca.55-2.4

Open Access: www.revistas.una.ac.cr/ambientales e-mail: revista.ambientales@una.ac.cr Espinoza-Cisneros E.

media resulta habitual el cultivo del café, banano y la ganadería de pequeña y mediana escala. En la cuenca baja destacan actividades productivas más intensificadas como la palma africana, manejada usualmente bajo la figura de cooperativa. También en la parte baja se da la ganadería $y$, en menor grado, el turismo.

A pesar de su riqueza ecológica y su baja densidad poblacional, en los últimos años la cuenca del Savegre ha estado sujeta a crecientes presiones antropogénicas, principalmente por la acuicultura intensiva, la expansión de la frontera agrícola y ganadera, así como por prácticas de pesca destructiva (SINAC, 2017). Los impactos de estas presiones se exacerban por los efectos de eventos hidrometeorológicos extremos en años recientes. La tormenta tropical Nate del 2017, por ejemplo, causó severas afectaciones sociales y ambientales a lo largo de la cuenca (SEPSA, 2018).

\subsection{Muestreo y diseño de encuestas}

Para esta investigación se realizaron encuestas a administradores de UP. Las encuestas capturaban diversos aspectos perceptivos sobre la calidad del agua fluvial en la cuenca del Savegre y sus amenazas asociadas. Se encuestaron a 109 administradores de UP en 15 comunidades a lo largo de la cuenca (Cuadro 1). Las encuestas se realizaron en persona, en visitas de campo intermitentes que se efectuaron de marzo del 2017 a octubre del 2018.

Cuadro 1. Lista de comunidades donde se realizaron las encuestas, ubicadas por sector de la cuenca y con sus información político-administrativa.

Table 1. List of communities where surveys were carried out, by watershed sector and with basic political-administrative information.

\begin{tabular}{cllll}
\hline \multicolumn{1}{c}{ Sector de cuenca } & \multicolumn{1}{c}{ Comunidad } & \multicolumn{1}{c}{ Provincia } & \multicolumn{1}{c}{ Cantón } & Distrito \\
\hline Cuenca Alta & San Gerardo & San José & Dota & Copey \\
& Providencia & San José & Dota & Copey \\
& Santa Eduviges & San José & Pérez Zeledón & Páramo \\
& Santo Tomás & San José & Pérez Zeledón & Páramo \\
& Los Ángeles & San José & Pérez Zeledón & Páramo \\
Cuenca Media & Savegre Abajo & San José & Pérez Zeledón & Río Nuevo \\
& Zaragoza & San José & Pérez Zeledón & Río Nuevo \\
& San Isidro & San José & Dota & Santa María \\
& El Llano & San José & Pérez Zeledón & Río Nuevo \\
& Piedras Blancas & San José & Pérez Zeledón & Río Nuevo \\
Cuenca Baja & Brujo & San José & Pérez Zeledón & Río Nuevo \\
& Santo Domingo & Puntarenas & Quepos & Savegre \\
& Quebrada Arroyo & San José & Tarrazú & San Lorenzo \\
& El Silencio-San Cristóbal & Puntarenas & Quepos & Savegre \\
& Río Blanco & San José & Dota & Copey \\
\hline
\end{tabular}

Para el muestreo de participantes, se obtuvieron listas de las UP a través de las Asociaciones de Desarrollo Integral de cada comunidad. Estas agrupaciones se consideraron las fuentes más apropiadas para dicho proceso, pues llevan un registro más preciso, actualizado y completo de las UP a nivel de comunidad en comparación con los registros municipales. Las listas proveídas

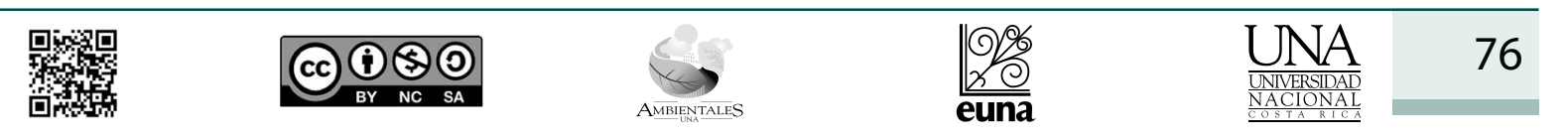




\section{Revista de CIENCIAS AMBIENTALES Tropical Journal of Environmental Sciences}

Revista de Ciencias Ambientales (Trop J Environ Sci)

e-ISSN: 2215-3896

(Julio-Diciembre, 2021) . Vol 55(2): 71-90

DOI: https://doi.org/10.15359/rca.55-2.4

Open Access: www.revistas.una.ac.cr/ambientales e-mail: revista.ambientales@una.ac.cr Espinoza-Cisneros E.

contenían información básica de la administración de las UP, incluyendo nombre, información de contacto y la actividad productiva primaria de la UP. Utilizando las listas como marco muestral, se aplicó un procedimiento de estratificación aleatoria para la selección de las muestras, tomando los tipos de actividades productivas primarias como "estratos". Esto se hizo con el fin de poder representar de una manera proporcional las actividades productivas principales (entre agricultura, ganadería y turismo) en cada comunidad. Al final, se encuestaron entre el $20 \%$ y el $50 \%$ de la totalidad de las UP en cada comunidad, basado en la cantidad registrada en las listas.

Para probar el instrumento, se realizaron inicialmente doce encuestas piloto en 6 comunidades distintas, distribuidas equitativamente en los tres sectores de la cuenca (dos en cuenca alta, dos en la media, dos en la baja). Luego de esta primera serie de encuestas piloto, se produjo una segunda iteración del instrumento; posteriormente se realizaron 5 encuestas piloto adicionales (dos en cuenca alta, dos en media y una en baja) para probar esta segunda versión. Luego de esta segunda fase piloto, se obtuvo el instrumento definitivo. El Cuadro 2 muestra información sociodemográfica general de los participantes.

Cuadro 2. Información sociodemográfica de los administradores de unidades productivas encuestados ( $\mathrm{n}=109)$. Table 2. Sociodemographic information of the surveyed land unit managers $(n=109)$.

\begin{tabular}{|c|c|c|c|c|c|}
\hline & $\begin{array}{l}\text { Edad } \\
\text { (promedio } \\
\text { años) }\end{array}$ & Sexo & Educación formal & $\begin{array}{l}\text { Originario(a) de } \\
\text { comunidad }\end{array}$ & $\begin{array}{c}\text { Tiempo de } \\
\text { residir en la } \\
\text { comunidad } \\
\text { (promedio años) }\end{array}$ \\
\hline $\begin{array}{l}\text { Todas las } \\
\text { muestras } \\
(n=109)\end{array}$ & 53.72 & $\begin{array}{l}95.4 \% \mathrm{~h} \\
4.6 \% \mathrm{~m}\end{array}$ & $\begin{array}{l}\text { Sin educación formal - } 6.4 \% \\
\text { Primaria - } 80 \% \\
\text { Secundaria }-8.2 \% \\
\text { Postsecundaria }-5.5 \%\end{array}$ & $64.2 \%$ & 41.2 \\
\hline $\begin{array}{l}\text { Cuenca alta } \\
(n=42)\end{array}$ & 49.52 & $100 \% \mathrm{~h}$ & $\begin{array}{l}\text { Sin educación formal - } 4.7 \% \\
\text { Primaria - } 83.3 \% \\
\text { Secundaria }-7.14 \% \\
\text { Postsecundaria }-4.7 \%\end{array}$ & $76.2 \%$ & 43.2 \\
\hline $\begin{array}{l}\text { Cuenca media } \\
(n=30)\end{array}$ & 53.96 & $\begin{array}{l}96.7 \% \mathrm{~h} \\
3.3 \% \mathrm{~m}\end{array}$ & $\begin{array}{l}\text { Sin educación formal - } 13.3 \% \\
\text { Primaria - } 80 \% \\
\text { Secundaria }-3.3 \% \\
\text { Postsecundaria }-3.3 \%\end{array}$ & $66.7 \%$ & 37.7 \\
\hline $\begin{array}{l}\text { Cuenca alta } \\
(n=37)\end{array}$ & 57.7 & $\begin{array}{l}89.2 \% \mathrm{~h} \\
10.8 \% \mathrm{~m}\end{array}$ & $\begin{array}{l}\text { Sin educación formal - } 2.7 \% \\
\text { Primaria }-75.7 \% \\
\text { Secundaria }-13.5 \% \\
\text { Postsecundaria }-8.1 \%\end{array}$ & $48.6 \%$ & 41.2 \\
\hline
\end{tabular}

\subsection{Selección, procesamiento y análisis de variables}

El Cuadro 3 describe las variables utilizadas para el análisis estadístico. Las percepciones sobre calidad del agua fluvial y sus amenazas fueron utilizadas como variables dependientes. La elección de las variables independientes se basó en observaciones de campo y en análisis sistemáticos del sistema socioecológico de la cuenca (ver Espinoza-Cisneros, 2018).

\begin{tabular}{|c|c|c|c|c|c|}
\hline 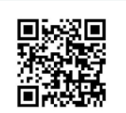 & (c) () (5) & $\underset{\text { AMBiENTALES }}{\longrightarrow}$ & $\frac{Q \%}{20}$ & $\frac{\text { UNA }}{\frac{\text { UNIVERSIDAD }}{\text { UNACIONAL }}}$ & 77 \\
\hline
\end{tabular}




\section{Revista de CIENCIAS AMBIENTALES Tropical Journal of Environmental Sciences}

Revista de Ciencias Ambientales (Trop J Environ Sci)

e-ISSN: 2215-3896

(Julio-Diciembre, 2021) . Vol 55(2): 71-90

DOI: https://doi.org/10.15359/rca.55-2.4

Open Access: www.revistas.una.ac.cr/ambientales e-mail: revista.ambientales@una.ac.cr Espinoza-Cisneros $\mathrm{E}$

Para el análisis estadístico, se utilizó el programa IBM SPSS versión 25. Las pruebas efectuadas buscaban diferencias significativas en las percepciones sobre la calidad del agua y los niveles de amenaza a la calidad del agua entre diferentes categorías de características sociodemográficas, económico-productivas y espaciales. Como la mayoría las variables fueron tratadas como ordinales y categóricas (nominales), se efectuaron pruebas no-paramétricas, particularmente Kruskall-Wallis H, Mann-Whitney U y Correlaciones Spearman. Los datos cumplieron con todos los supuestos de las pruebas no-paramétricas efectuadas, incluidos los niveles de medición de las variables dependientes e independientes, la independencia de las observaciones, y variabilidad.

Cuadro 3. Resumen de las variables utilizadas en el análisis estadístico.

Table 3. Summary of variables used in the statistical analysis.

\begin{tabular}{|c|c|c|c|}
\hline Variable & Descripción & Tipo & $\begin{array}{l}\text { Escala de } \\
\text { medición }\end{array}$ \\
\hline $\begin{array}{l}\text { Percepciones sobre calidad } \\
\text { del agua fluvial (variable } \\
\text { dependiente) }\end{array}$ & $\begin{array}{l}\text { Esta variable captura las percepciones sobre el estado } \\
\text { general de la calidad del agua en la cuenca en su totalidad } \\
\text { y no para un sector en específico. La variable se colectó } \\
\text { utilizando una escala de clasificación de } 5 \text { puntos, que iba } \\
\text { desde calidad del agua "excelente" hasta "muy mala". La } \\
\text { resolución de medición de } 5 \text { niveles se consideró apropiada } \\
\text { con base en las encuestas piloto. }\end{array}$ & Ordinal & $\begin{array}{l}\text { Escala de } 5 \\
\text { puntos }\end{array}$ \\
\hline $\begin{array}{l}\text { Percepciones sobre nivel } \\
\text { de amenaza a la calidad } \\
\text { del agua fluvial (variable } \\
\text { dependiente) }\end{array}$ & $\begin{array}{l}\text { Captura percepciones sobre los niveles de amenaza a } \\
\text { la calidad del agua fluvial, por diversas causas (p.ej. } \\
\text { agroquímicos, sedimentación, aguas negras) para el sistema } \\
\text { de la cuenca en su totalidad. El ítem no se formuló para } \\
\text { amenazas específicas, sino más bien para obtener un valor } \\
\text { consolidado que considerara las amenazas en su conjunto. }\end{array}$ & Ordinal & $\begin{array}{l}\text { Escala de } 5 \\
\text { puntos }\end{array}$ \\
\hline Sector de la cuenca & $\begin{array}{l}\text { Los sectores se dividieron en cuenca alta, media y baja, } \\
\text { basado en consideraciones tanto biofísicas (p.ej. topografía, } \\
\text { hidrografía, ecosistemas) como socioeconómicas (p.ej. } \\
\text { actividades productivas, uso de la tierra). Por ende, los tres } \\
\text { sectores presentan contextos socioecológicos distintos. }\end{array}$ & Categórica & $\begin{array}{l}\text { Tres categorías } \\
\text { de sectores: } \\
\text { cuenca alta, } \\
\text { cuenca media, } \\
\text { cuenca baja }\end{array}$ \\
\hline Edad & $\begin{array}{l}\text { La edad es una variable que suele incidir en las } \\
\text { cogniciones ambientales (Gifford y Nilsson, 2014). En } \\
\text { el caso de la cuenca del Savegre, se sabe que inciden en } \\
\text { la adopción de prácticas productivas proambientales } \\
\text { (Espinoza-Cisneros, 2020). }\end{array}$ & Continua & - \\
\hline $\begin{array}{l}\text { Grupos de niveles de } \\
\text { educación formal }\end{array}$ & $\begin{array}{l}\text { Nivel educativo formal también es usado frecuentemente } \\
\text { en estudios sobre percepciones ambientales, debido a } \\
\text { su potencial influencia (Hines et al., 1987; Kollmuss y } \\
\text { Agyeman, 2002). Para este trabajo, se consideraron } 4 \\
\text { categorías: sin educación formal, educación primaria } \\
\text { cursada o completa, educación secundaria cursada o } \\
\text { completa, y estudios postsecundarios (universidad, } \\
\text { diplomado, etc.). }\end{array}$ & Categórica & $\begin{array}{l}4 \text { categorías (ver } \\
\text { descripción) }\end{array}$ \\
\hline
\end{tabular}

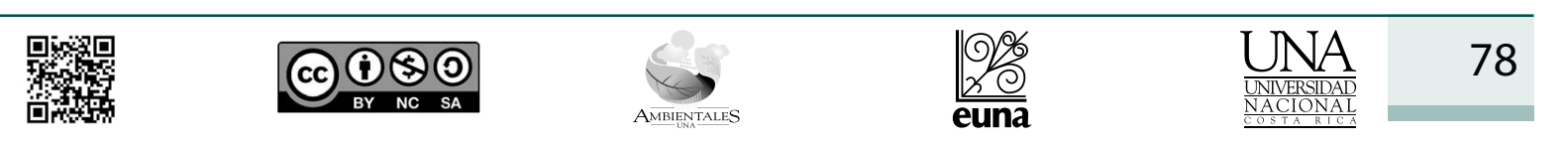




\section{Revista de CIENCIAS AMBIENTALES Tropical Journal of Environmental Sciences}

Revista de Ciencias Ambientales (Trop J Environ Sci)

e-ISSN: 2215-3896

(Julio-Diciembre, 2021) . Vol 55(2): 71-90

DOI: https://doi.org/10.15359/rca.55-2.4

Open Access: www.revistas.una.ac.cr/ambientales e-mail: revista.ambientales@una.ac.cr

Espinoza-Cisneros E.

\begin{tabular}{|c|c|c|c|}
\hline Variable & Descripción & Tipo & $\begin{array}{l}\text { Escala de } \\
\text { medición }\end{array}$ \\
\hline Distancia al río principal & $\begin{array}{l}\text { Los factores espaciales pueden influir considerablemente } \\
\text { en las percepciones ambientales en diversos contextos. En } \\
\text { este caso, se utilizaron tres rangos de distancias entre las } \\
\text { unidades productivas y los cauces de los ríos principales. } \\
\text { Se usaron rangos ya que las distancias exactas eran difíciles } \\
\text { de determinar debido a las extensiones variables de las } \\
\text { propiedades, además del carácter fragmentado de muchas. } \\
\text { También, porque hubo casos donde el administrador fue } \\
\text { encuestado fuera de la finca (p.ej., en una casa de recreo o bien } \\
\text { en la de un familiar o miembro de la comunidad), por lo que } \\
\text { se dificultaba estimar distancias más exactas de la UP al río. }\end{array}$ & Ordinal & $\begin{array}{l}\text { 0-249m (Rango } \\
\text { 1), 250-499 } \\
\text { m (Rango 2), } \\
\geq 500 \mathrm{~m} \text { (Rango } \\
\text { 3) }\end{array}$ \\
\hline $\begin{array}{l}\text { Posesión de título de } \\
\text { propiedad }\end{array}$ & $\begin{array}{l}\text { La tenencia de la tierra es un tema controversial en la } \\
\text { cuenca del Savegre, particularmente por las limitaciones } \\
\text { de muchos productores para obtener la titulación de } \\
\text { tierras dentro del área de la Reserva Forestal Los Santos. Se } \\
\text { hipotetizó que, por la seguridad en la tenencia, las personas } \\
\text { con el título de propiedad tendrían percepciones distintas } \\
\text { de los grupos sin el título de propiedad. }\end{array}$ & Dicotómica & Sí/No \\
\hline $\begin{array}{l}\text { Actividad productiva } \\
\text { primaria }\end{array}$ & $\begin{array}{l}\text { En esta variable se consideraron las tres actividades } \\
\text { productivas predominantes en la cuenca: la agricultura, } \\
\text { la ganadería y el turismo. Se excluyeron de este análisis } \\
\text { las actividades de acuicultura y la forestal, ya que, a pesar } \\
\text { de que se dan en la cuenca, ninguna UP muestreada las } \\
\text { reportó como actividades productivas primarias. }\end{array}$ & Categórica & $\begin{array}{l}\text { Agricultura, } \\
\text { Ganadería, } \\
\text { Turismo }\end{array}$ \\
\hline $\begin{array}{l}\text { Nivel de ingresos de } \\
\text { actividad productiva } \\
\text { primaria }\end{array}$ & $\begin{array}{l}\text { Los niveles de ingresos también han sido comúnmente } \\
\text { considerados en investigaciones sobre cogniciones } \\
\text { ambientales (Clark et al., 2003). En el instrumento de la } \\
\text { encuesta se incluyó un ítem para capturar percepciones sobre } \\
\text { los ingresos derivados de la UP. Se preguntó lo siguiente: } \\
\text { “Cómo calificaría el total de ingresos generado por esta unidad } \\
\text { productiva en el último año?”, utilizando una escala de } 5 \text { puntos } \\
\text { que iba desde "muy bueno" hasta "muy malo". }\end{array}$ & Ordinal & $\begin{array}{l}\text { Escala de } 5 \\
\text { puntos }\end{array}$ \\
\hline
\end{tabular}

De forma complementaria al análisis estadístico, se examinaron percepciones sobre los factores que más afectan la calidad del agua fluvial, sobre la temporalidad de los cambios en la calidad del agua fluvial, así como las principales amenazas a esa calidad. Para capturar estas percepciones, se utilizaron ítems abiertos de respuesta corta, algunos con carácter ordinal (p.ej., "En orden de importancia, mencione algunas de las principales amenazas actuales a la calidad del agua del río Savegre”); también se utilizaron ítems cerrados de selección simple (p.ej., “¿La calidad del agua en el Savegre ha mejorado, empeorado o se ha mantenido igual en los últimos años?"). Para cada amenaza mencionada, se incluyó además un ítem de escala de 4 puntos para capturar las percepciones sobre qué tanto hacen las autoridades locales y nacionales para atender esa amenaza. Los valores de este ítem luego fueron convertidos a una escala de 10 para facilitar su interpretación. Finalmente, las respuestas a las preguntas fueron codificadas con el fin de

\begin{tabular}{|c|c|c|c|c|c|}
\hline 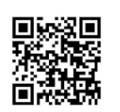 & (c) (i) (\$) & $\underset{\text { AMBIENTALES }}{\Leftrightarrow}$ & $\frac{9 \%}{\text { euna }}$ & 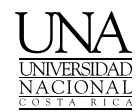 & 79 \\
\hline
\end{tabular}




\section{Revista de CIENCIAS AMBIENTALES Tropical Journal of Environmental Sciences}

Revista de Ciencias Ambientales (Trop J Environ Sci)

e-ISSN: 2215-3896

(Julio-Diciembre, 2021) . Vol 55(2): 71-90

DOI: https://doi.org/10.15359/rca.55-2.4

Open Access: www.revistas.una.ac.cr/ambientales e-mail: revista.ambientales@una.ac.cr Espinoza-Cisneros E.

clasificarlas y poder examinar los patrones de respuesta utilizando estadística descriptiva. Luego se hicieron rankings de las principales respuestas según su frecuencia de mención.

\section{Resultados}

\subsection{Análisis estadístico}

El Cuadro 4 resume los resultados de las pruebas estadísticas efectuadas. Las percepciones sobre calidad del agua fluvial difirieron significativamente entre los sectores de la cuenca $(\mathrm{p}=$ $0.001)$, niveles educativos formales $(\mathrm{p}=0.042)$, distancias al río principal $(\mathrm{p}=0.008)$ y entre los tipos de actividad productiva primaria $(\mathrm{p}=0.03)$. Las percepciones sobre el nivel de amenaza a la calidad del agua fluvial también difirieron significativamente entre los sectores de la cuenca ( $\mathrm{p}$ $=0.011)$, distancias del río principal $(\mathrm{p}=0.028)$ y con los tipos de actividad productiva primaria $(\mathrm{p}=0.015)$. Para esta variable de amenazas, sin embargo, no fue estadísticamente significativo el valor $p$ del nivel educativo formal $(\mathrm{p}=0.108)$.

Cuadro 4. Resumen de resultados de pruebas estadísticas para determinar diferencias entre las percepciones ambientales por variables espaciales, sociodemográficas y económico-productivas.

Table 4. Summary of results from statistical tests for determining differences in environmental perceptions by spatial, sociodemographic, and economic-productive variables

\begin{tabular}{|c|c|c|c|c|}
\hline Variables dependientes & $\begin{array}{c}\text { Variables independientes } \\
\text { (grupos) }\end{array}$ & $\begin{array}{c}\text { Prueba } \\
\text { estadística } \dagger\end{array}$ & Valor de prueba $T$ & Sig. \\
\hline \multirow[t]{7}{*}{ Calidad del agua fluvial $(n=109)$} & Sector cuenca & KW & $\chi^{2(2)}=13.454$ & $0.001^{* *}$ \\
\hline & Edad & SP & $r_{s}(107)=-0.056$ & 0.564 \\
\hline & Nivel educativo formal & KW & $\chi^{2(3)}=8.218$ & $0.042^{*}$ \\
\hline & Distancia al río (categorías) & KW & $\chi^{2(2)}=9.662$ & $0.008^{\star *}$ \\
\hline & Título de propiedad & MW & $\mathrm{U}=1753, \mathrm{z}=1.752$ & 0.8 \\
\hline & Tipo de actividad primaria & KW & $\chi 2(2)=11.827$ & $0.03^{*}$ \\
\hline & Categoría de ingresos & KW & $\chi^{2(3)}=2.648$ & 0.449 \\
\hline \multirow{7}{*}{$\begin{array}{l}\text { Nivel de amenaza a la calidad del } \\
\text { agua fluvial }(n=107)\end{array}$} & Sector cuenca & KW & $\chi^{2(2)}=9.011$ & $0.011^{\star}$ \\
\hline & Edad & SP & $r_{s}(105)=0.058$ & 0.556 \\
\hline & Nivel educativo formal & KW & $\chi^{2(3)}=6.068$ & 0.108 \\
\hline & Distancia al río (categorías) & KW & $\chi^{2(2)}=7.133$ & $0.028^{\star}$ \\
\hline & Título de propiedad & MW & $\mathrm{U}=1561, \mathrm{z}=0.887$ & 0.375 \\
\hline & Tipo de actividad primaria & KW & $\chi 2(2)=8.453$ & $0.015^{*}$ \\
\hline & Categoría de ingresos & KW & $\chi^{2(3)}=0.562$ & 0.905 \\
\hline $\begin{array}{l}{ }_{* \star}^{*}<0.05 \\
{ }^{*}<0.01\end{array}$ & $\begin{array}{l}\dagger K W \text { : Prueba Kruskall-Wallis } H \\
\text { SP: Correlación Spearman } \\
\text { MW: Prueba Mann-Whitney U }\end{array}$ & & & \\
\hline
\end{tabular}

Por otra parte, las pruebas post-hoc revelaron que las percepciones sobre calidad del agua fluvial fueron significativas para los sectores de cuenca alta con media $(\mathrm{p}=0.001)$ y cuenca media con baja $(\mathrm{p}=0.002)$. Para las percepciones sobre niveles de amenaza al agua fluvial, los

\begin{tabular}{|c|c|c|}
\hline 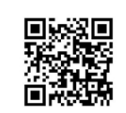 & (c) (i) & 80 \\
\hline
\end{tabular}




\section{Revista de CIENCIAS AMBIENTALES Tropical Journal of Environmental Sciences}

Revista de Ciencias Ambientales (Trop J Environ Sci)

e-ISSN: 2215-3896

(Julio-Diciembre, 2021) . Vol 55(2): 71-90

DOI: https://doi.org/10.15359/rca.55-2.4

Open Access: www.revistas.una.ac.cr/ambientales e-mail: revista.ambientales@una.ac.cr Espinoza-Cisneros E.

análisis post hoc también revelaron diferencias significativas entre los mismos sectores de cuenca alta con media $(\mathrm{p}=0.006)$ y cuenca media con baja $(\mathrm{p}=0.011)$.

En cuanto a la variable del nivel educativo formal (solo significativa para la variable de calidad del agua fluvial), la diferencia más marcada se dio entre los que no tienen educación formal y los que asistieron a secundaria $(\mathrm{p}=0.037)$. Los demás binarios grupales no presentaron diferencias significativas. Para ambas percepciones analizadas estadísticamente, se presentaron diferencias significativas entre las actividades productivas primarias de ganadería y agricultura ( $\mathrm{p}=0.001$ para la variable de calidad del agua $\mathrm{y} \mathrm{p}=0.013$ para la de amenazas).

Finalmente, en cuanto a las relaciones encontradas entre los rangos de distancia al río principal, para las percepciones de calidad del agua, la relación significativa fue entre el Rango 1 (de 0 a 249 metros) y el Rango 2 (de 250 a 499 metros) $(\mathrm{p}=0.002)$. La relación entre estos fue significativa para el caso de las percepciones de amenazas $(\mathrm{p}=0.013)$, además de la relación entre los Rangos 2 y 3 ( $\geq 500$ metros) ( $\mathrm{p}=0.043)$.

\subsection{Factores influyentes y temporalidad de los cambios en la calidad del agua fluvial}

El Cuadro 5 muestra una lista, en orden de importancia, de los factores que, según los administradores encuestados, influyen en la condición de la calidad del agua del río Savegre. La cobertura boscosa de la cuenca (que se estima ronda el $75 \%$ - Mattey, 2014) fue mencionada como principal factor favorecedor de la calidad del agua. Cercanamente vinculado con este factor está la protección de nacientes, la cual destacó como tercera más importante. La poca contaminación de las aguas se ubicó en segundo nivel de importancia, mientras que en el cuarto y quinto respectivamente están la conciencia ambiental de los residentes y la baja densidad poblacional.

Por otro lado, los factores que desfavorecen la calidad del agua fluvial están mayormente asociados a actividades productivas dentro de la cuenca. En primer lugar, destaca el uso de agroquímicos; en segundo lugar, están los residuos derivados de la cría de cerdos, seguido en tercer lugar por los residuos de los beneficios del café, y, de cuarto lugar, por las granjas de acuicultura de truchas. En quinto lugar, se ubicó la pérdida de bosque, asociada a procesos de sedimentación y transporte de material hacia cursos fluviales.

Cuadro 5. Ranking de principales factores influyentes (que favorecen y desfavorecen) en la calidad del agua del río Savegre, según resultados de encuestas.

Table 5. Ranking of main influencing factors (favorable and unfavorable) in the Savegre river's water quality, as per survey results.

\begin{tabular}{cll}
\hline Ranking & \multicolumn{1}{c}{ Factores que favorecen la calidad del agua } & \multicolumn{1}{c}{ Factores que desfavorecen la calidad del agua } \\
\hline 1 & Amplia cobertura boscosa & Uso de agroquímicos en actividades productivas \\
2 & Poca contaminación de las aguas & Actividad de cría de cerdos \\
3 & Protección de nacientes de agua & Residuos de los beneficios de café \\
4 & Conciencia de los residentes & Residuos de las granjas de truchas \\
5 & Baja densidad poblacional & Pérdida de cobertura boscosa \\
\hline
\end{tabular}

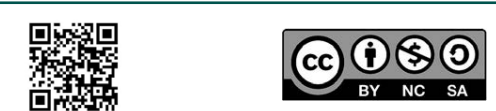

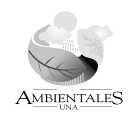




\section{Revista de CIENCIAS AMBIENTALES Tropical Journal of Environmental Sciences}

Revista de Ciencias Ambientales (Trop J Environ Sci)

e-ISSN: 2215-3896

(Julio-Diciembre, 2021) . Vol 55(2): 71-90

DOI: https://doi.org/10.15359/rca.55-2.4

Open Access: www.revistas.una.ac.cr/ambientales e-mail: revista.ambientales@una.ac.cr Espinoza-Cisneros $\mathrm{E}$.

En cuanto a la temporalidad en los cambios en la calidad del agua fluvial (Cuadro 6), para casi el $50 \%$ de los administradores la calidad del agua del río ha desmejorado en los últimos años, en promedio desde hace 18.5 años. Para un $37 \%$, la calidad del agua se ha mantenido igual, mientras que para un $13 \%$ ha mejorado su condición. Para estos últimos, ese mejoramiento se empezó a dar, en promedio, hace 21 años.

Cuadro 6. Resumen de resultados sobre la temporalidad de los cambios en la calidad del agua fluvial en la cuenca del río Savegre.

Table 6. Summary of results about the temporal aspect of changes in fluvial water quality in the Savegre river watershed

\begin{tabular}{lccccc}
\hline \multicolumn{1}{c}{ Categoría } & Porcentaje & Promedio (años) & Rango (años) & Modo (años) & SD (años) \\
\hline Calidad del agua ha desmejorado & 49.5 & & & & \\
¿Cuándo empezó a desmejorar? & - & 18.5 & $4-50$ & 10 & 11.91 \\
Calidad del agua está igual & 37 & & & & \\
Calidad del agua está mejor & 13 & & & & \\
¿Cuándo empezó a mejorar? & - & 21 & $5-45$ & 20 & 11.38 \\
\hline
\end{tabular}

\subsection{Amenazas a la calidad del agua fluvial}

La Figura 3 sintetiza los resultados de la priorización de amenazas a la calidad del agua fluvial en la cuenca del río Savegre. Las amenazas fueron categorizadas por niveles de prioridad (Nivel 1, el más alto; Nivel 2, el intermedio; y Nivel 3, el menos prioritario) y, por cada nivel, fueron situadas en orden de importancia según su frecuencia de mención. En el Nivel 1 y con mayor frecuencia de mención está la pérdida de cobertura boscosa con un $26.8 \%$ de los administradores ubicándola aquí. Un adicional $15.5 \%$ de los participantes sitúan esta misma amenaza en el Nivel 2 en la segunda posición de mayor mención. Ya en el Nivel 3 no aparece, lo que indica que es una amenaza vista mayormente como prioritaria. Además, recibe una calificación de 5.87 de 10 (la segunda más alta para todas las amenazas) en los niveles de atención por parte de las autoridades para minimizar los impactos negativos de la amenaza.

Muy de cerca a la pérdida de bosque le sigue la amenaza de acuicultura intensiva y prácticas de pesca destructiva, como el uso de venenos, explosivos, y el trasmallo. En el Nivel 1 esta amenaza se ubica en segundo lugar con un $22.7 \%$ de mención, mientras que en el Nivel 2 pasa al primer lugar, pero con menos porcentaje de mención (17.2\%). Su conducta entre los Niveles 1 y 2 es similar a la amenaza de pérdida de bosque, por lo que estas dos podrían considerarse entre las más prominentes. Por otra parte, esta amenaza recibe una calificación de 5.25 de 10 en atención por parte de las autoridades locales y nacionales.

\begin{tabular}{|c|c|c|c|c|c|}
\hline 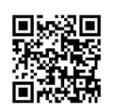 & (c) (1) & $\underset{\text { AMBENENALIES }}{\infty}$ & $\frac{1 \%}{\text { euna }}$ & 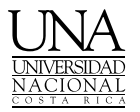 & 82 \\
\hline
\end{tabular}




\section{Revista de CIENCIAS AMBIENTALES Tropical Journal of Environmental Sciences}

Revista de Ciencias Ambientales (Trop J Environ Sci)

e-ISSN: 2215-3896

(Julio-Diciembre, 2021) . Vol 55(2): 71-90

DOI: https://doi.org/10.15359/rca.55-2.4

Open Access: www.revistas.una.ac.cr/ambientales e-mail: revista.ambientales@una.ac.cr Espinoza-Cisneros E.

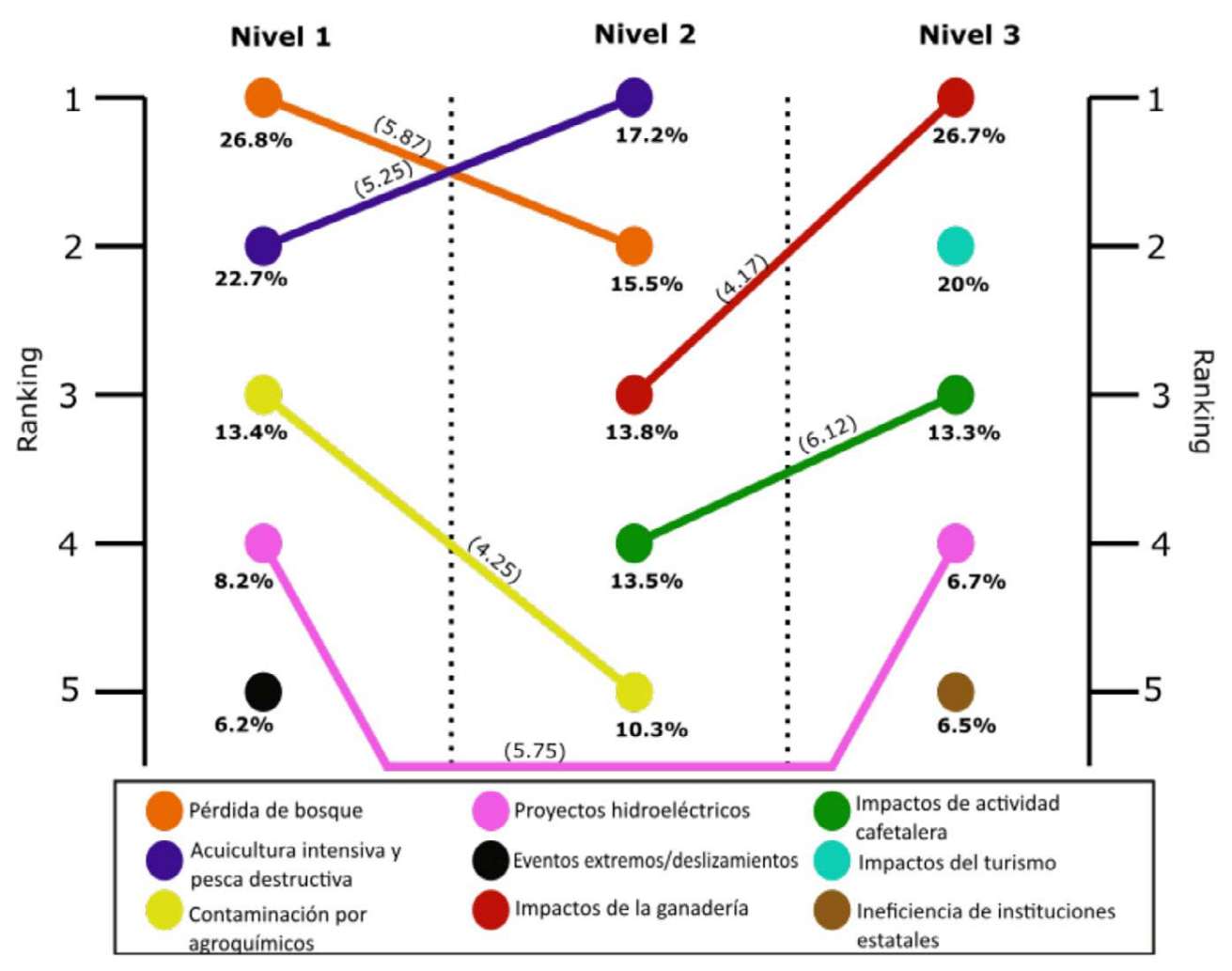

Figura 3. Ranking de las principales amenazas a la calidad del agua fluvial, según niveles de priorización (Nivel 1 siendo el más alto, Nivel 2 el intermedio, y el Nivel 3 el menos prioritario). Los valores porcentuales en cada punto representan el porcentaje de mención tomando en cuenta todas las encuestas efectuadas. El valor entre paréntesis representa la calificación, en una escala de 1 a 10, del nivel de atención que las autoridades locales y nacionales le dan a la amenaza, siendo 10 la máxima calificación (es decir, un nivel de atención alto).

Figure 3. Ranking of main threats to fluvial water quality, by priority levels. (Level 1 being the highest priority, Level 2 intermediate priority, and Level 3 lowest priority). Percentage levels for each point represent the percentage of mention, taking all surveys into account. Value in parenthesis represents the score given, on a scale from 1 to 10 , to the job local and national authorities are doing to address the threat, being 10 the maximum score (i.e., doing a lot to address the threat).

Evidenciando también niveles altos de importancia como amenaza, la contaminación por agroquímicos se ubicó en la tercera posición del Nivel 1 con 13.4 \% de mención, pasando luego a la quinta posición del Nivel 2 con $10.3 \%$ de mención. Tuvo, además, una valoración promedio de 4.25 de 10 en la atención por parte de las autoridades. La amenaza que representan los proyectos hidroeléctricos se ubicó en la posición 4 del Nivel 1 con un $8.2 \%$ de mención, y vuelve a aparecer hasta el Nivel 3 en esa misma posición, esta vez con un 6.7 \% de mención. La valoración de atención por parte de las autoridades fue de un 5.75 de 10 para el caso de los proyectos hidroeléctricos. En la última posición del Nivel 1, con un 6.2 \% de mención, se ubicó la amenaza

\begin{tabular}{|c|c|c|}
\hline 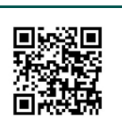 & (c) (i) @) (2) & 83 \\
\hline
\end{tabular}




\section{Revista de CIENCIAS AMBIENTALES Tropical Journal of Environmental Sciences}

Revista de Ciencias Ambientales (Trop J Environ Sci)

e-ISSN: 2215-3896

(Julio-Diciembre, 2021) . Vol 55(2): 71-90

DOI: https://doi.org/10.15359/rca.55-2.4

Open Access: www.revistas.una.ac.cr/ambientales e-mail: revista.ambientales@una.ac.cr Espinoza-Cisneros E.

por eventos extremos asociados al cambio climático, principalmente deslizamientos en laderas. Esta amenaza no apareció de nuevo en los otros niveles.

Dos nuevas amenazas aparecen en el Nivel 2: los impactos asociados a la ganadería y los asociados a la actividad cafetalera. La primera de estas se ubica en la tercera posición con un $13.8 \%$ de mención, luego pasa a la primera posición del Nivel 3 con un $26.7 \%$ de mención; es decir, se caracteriza como una amenaza de prioridad intermedia-baja, pero con porcentajes importantes de mención. El valor de atención de esta amenaza por parte de autoridades es de 4.17 de 10. La segunda amenaza nueva que aparece en este nivel, los impactos de la actividad cafetalera, muestra un comportamiento similar al anterior, aunque con menos frecuencia de mención. Por ejemplo, al igual que la amenaza de impactos de la ganadería, los impactos por la actividad cafetalera aparecen recién en el Nivel 2 y luego ascienden de posición en el Nivel 3, en este caso con porcentajes de mención muy similares (13.5 \% en el Nivel 2 y $13.3 \%$ en el 3). Finalmente, en el Nivel 3 aparecen dos amenazas nuevas: los impactos del turismo en segundo lugar y con un $20 \%$ de mención, y la ineficiencia en las instituciones del estado en un quinto lugar, con un $6.5 \%$ de mención.

\section{Discusión}

Las percepciones ambientales son constructos cognitivos que, junto con otros factores tanto internos como externos, subyacen las acciones humanas sobre el ambiente. Entre los factores externos está el contexto socioecológico en el cual se desenvuelve el agente que, a través de una relación bidireccional dinámica (Figura 1), es influido por, y a su vez influye, en las cogniciones (Hukkinen, 2012). Las diferencias significativas encontradas en las percepciones para los diversos sectores de cuenca refuerzan la evidencia de esta relación entre contexto y cogniciones. Como suele darse en las cuencas hidrográficas, las dinámicas socioecológicas varían mucho entre sus sectores, no solo por sus diferencias ecogeomorfológicas e hidrológicas, sino también socioeconómicas. En la cuenca alta del río Savegre, por ejemplo, predomina la cobertura boscosa, en parte por una abrupta topografía que históricamente ha desincentivado los asentamientos humanos y a su vez favorecido los regímenes de protección y conservación. En la cuenca media hay menos cobertura boscosa, más actividades productivas agrícolas y ganaderas, así como mayores densidades de población comparado a la cuenca alta. En la cuenca baja se dan actividades productivas más intensificadas, como monocultivos de palma africana, una geomorfología más plana, y comunidades más dispersas. Por ende, los resultados aquí obtenidos resaltan la influencia de esos contextos socioecológicos en las cogniciones ambientales.

Como se mencionó antes, las variables espaciales de proximidad también pueden jugar un rol importante en las percepciones ambientales. La influencia en las percepciones se puede dar debido a que la proximidad permite una mayor exposición a ciertos fenómenos y, con ello, a observaciones más frecuentes y exhaustivas. En comunidades de la cuenca alta y baja del río Savegre, muchos asentamientos y parcelas se encuentran a menos de 250 metros del curso fluvial principal. Esto es claramente observable, por ejemplo, en el patrón espacial de asentamiento elongado en la comunidad de San Gerardo de Dota, distribuido a lo largo de las márgenes del río

\begin{tabular}{|c|c|c|c|c|c|}
\hline 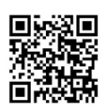 & (c) (i) (9) & $\underset{\text { AMBIENANALES }}{\infty}$ & $\frac{O \%}{2 \%}$ & 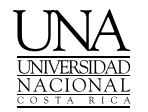 & 84 \\
\hline
\end{tabular}




\section{Revista de CIENCIAS AMBIENTALES Tropical Journal of Environmental Sciences}

Revista de Ciencias Ambientales (Trop J Environ Sci)

e-ISSN: 2215-3896

(Julio-Diciembre, 2021) . Vol 55(2): 71-90

DOI: https://doi.org/10.15359/rca.55-2.4

Open Access: www.revistas.una.ac.cr/ambientales e-mail: revista.ambientales@una.ac.cr Espinoza-Cisneros E.

Savegre y usualmente con las edificaciones y vías a distancias de menos de 200 metros del lecho del río. Las comunidades de Santo Tomás, Los Ángeles, El Brujo, y El Llano también presentan patrones de asentamiento similares. Es importante resaltar, no obstante, que la proximidad no solo facilita la observación visual, sino que también favorece los sentidos olfativos y de oído para la formación de esquemas perceptivos sobre la calidad del agua fluvial. Sin embargo, hacen falta más estudios que profundicen en esta relación entre proximidad a cuerpos de agua y percepciones con el fin de proveer insumos para el manejo del recurso hídrico.

En este estudio se encontraron diferencias significativas en las percepciones ambientales de los administradores dedicados a diferentes actividades productivas primarias, principalmente entre ganadería y agricultura. Es difícil determinar una razón convincente para esta diferencia, no obstante, en la cuenca del Savegre, esto podría estar ligado a dos factores: por un lado, la actividad ganadera tiene una ligera mayor dependencia del agua fluvial comparado a la agricultura, ya que muchas UP dedicadas a la ganadería utilizan quebradas o riachuelos de la propiedad para abastecer de agua al ganado, ya sea a través de bebederos, o bien, a través de un acceso directo del ganado al cuerpo de agua. Como segundo factor están las capacitaciones que los administradores han recibido a través de, por ejemplo, programas de extensión rural en las diferentes actividades productivas. Estos programas de extensión, así como el acceso a ellos, varían mucho entre las actividades productivas, lo que puede estar incidiendo en las percepciones ambientales.

Como el tema de la tenencia de la tierra es controversial en la cuenca del Savegre, inicialmente se hipotetizó de que este factor iba a incidir significativamente en las percepciones ambientales. Si bien la tenencia de la tierra se ha vinculado con la adopción (o no adopción) de prácticas de conservación en ciertos contextos (p.ej. Bremer et al., 2014; Soule et al., 2000), su relación con las cogniciones y decisiones ambientales ha sido tenue posiblemente por la simplificación de la variable de tenencia a la hora de medirla (Prokopy et al., 2019), algo que, de hecho, sucedió en el presente estudio. Sin embargo, puede suceder que, en algunos contextos, la tenencia de la tierra no sea vista como un factor de peso en los esquemas de toma de decisiones a nivel de UP, situándose por debajo de, por ejemplo, consideraciones económicas o culturales. Una interrogante para futuros estudios en la cuenca es la relación que podría tener una mayor seguridad en la tenencia de la tierra con las acciones ambientales en las UP.

De las percepciones sobre los factores que favorecen la calidad del agua fluvial, resalta el hecho de que los administradores tienen claro, por un lado, que la cuenca es un sistema funcionalmente interdependiente entre sectores y, por otro, que los ecosistemas boscosos tienen funciones vitales para el bienestar humano. En cuanto a lo primero, los productores en general son conscientes de la conexión hidrológica y ecológica entre los sectores de la cuenca y, con ello, de la importancia de una coordinación conjunta. De hecho, desde inicios de la década del 2000, se han establecido mecanismos de coordinación intercomunitarios e intersectoriales, con el fin de articular canales de comunicación y planificación. Ejemplo de estos mecanismos en la cuenca del Savegre ha sido la creación del Consejo de Cuenca (Mattey, 2014), así como los esfuerzos de diálogo conjunto en torno al desarrollo de proyectos hidroeléctricos. Aunque rescatables,

\begin{tabular}{|c|c|c|c|c|c|}
\hline 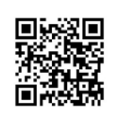 & (c) (1) (9) & $\overbrace{\text { AMBENTILIES }}$ & $\frac{9 \%}{20}$ & 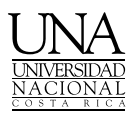 & 85 \\
\hline
\end{tabular}




\section{Revista de CIENCIAS AMBIENTALES Tropical Journal of Environmental Sciences}

Revista de Ciencias Ambientales (Trop J Environ Sci)

e-ISSN: 2215-3896

(Julio-Diciembre, 2021) . Vol 55(2): 71-90

DOI: https://doi.org/10.15359/rca.55-2.4

Open Access: www.revistas.una.ac.cr/ambientales e-mail: revista.ambientales@una.ac.cr Espinoza-Cisneros E.

algunos de estos esfuerzos han flaqueado por una falta de participación y seguimiento por parte de los miembros involucrados.

Por último, vale resaltar las percepciones de los administradores sobre los impactos que tienen las diversas actividades productivas que se desarrollan actualmente en la salud de la cuenca. Surge una especial preocupación por el uso indebido de agroquímicos y las prácticas de pesca destructiva, siendo estas últimas muy difíciles de regular por parte de las autoridades. En cuanto al cultivo de truchas, si bien se han documentado sus impactos ecológicos en ciertas comunidades de la cuenca (Naranjo, 2016), aún hace falta un panorama más amplio sobre dónde, cómo y por qué estas actividades productivas directamente dependientes del río afectan la ecología fluvial. Es notorio también cómo se percibe una atención alta de las autoridades para atender los impactos de la actividad cafetalera, por lejos el cultivo más abundante en la cuenca. Esta amenaza obtuvo la nota más alta en este ítem (6.12 de 10; ver Figura 3). Esto se puede deber, primero, a una mayor familiarización del productor con la actividad cafetalera, considerando que es el cultivo con mayor presencia en la cuenca y, en segundo lugar, a una mayor organización de ese sector a través de cooperativas, muchas de las cuales siguen normas internacionales de certificación social y ambiental, y poseen servicios robustos de extensión agrícola.

\section{Conclusiones}

Para la gestión ambiental efectiva es indispensable entender los patrones cognitivos de los agentes modificadores del entorno, considerando que las cogniciones preceden las decisiones y acciones de manejo. Este entendimiento, por ejemplo, es un insumo vital para los diagnósticos en instrumentos de planificación territorial, así como para el diseño de soluciones normativas a problemas ambientales apremiantes, particularmente en paisajes productivos. Este tipo de insumos también son importantes para lograr "alinear" las políticas y mecanismos regulatorios ambientales con las actitudes, valores, y percepciones compartidas por la sociedad.

Con el afán de responder a esto último, el presente estudio se propuso examinar las percepciones ambientales de administradores de unidades productivas sobre calidad del agua fluvial, así como sobre las amenazas a esa calidad, en la cuenca del río Savegre, Costa Rica, que constituye un microcosmos de retos socioambientales en los trópicos. Un aporte relevante, por ende, consiste en el entendimiento de los factores que inciden en las diferencias perceptuales sobre calidad del agua fluvial en este contexto particular, así como las presiones antropogénicas que se perciben como más apremiantes. De forma específica, es posible afirmar que este estudio halló que el sector de la cuenca, la distancia al río principal, los tipos de actividad primaria desarrolladas en la unidad productiva, así como el nivel educativo formal, inciden significativamente en las percepciones ambientales sobre calidad del agua fluvial de los administradores. Además, para estos administradores, los factores que más amenazan la calidad del agua fluvial están asociados a crecientes presiones antropogénicas en la cuenca como la expansión de las fronteras agrícolas y ganaderas, así como prácticas ilegales de pesca en el río, lo que evidencia un reconocimiento de los impactos ecológicos que conllevan estas actividades en los ecosistemas fluviales.

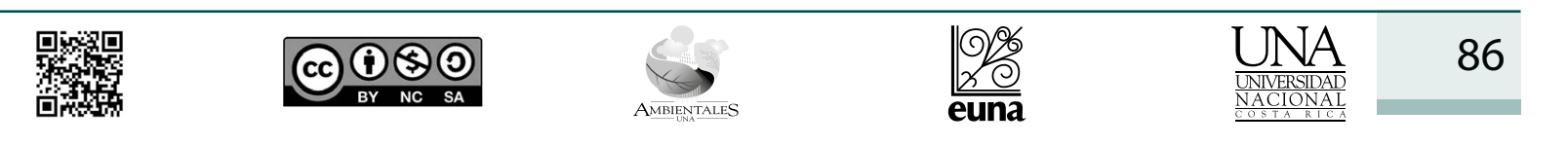




\section{Revista de CIENCIAS AMBIENTALES Tropical Journal of Environmental Sciences}

Revista de Ciencias Ambientales (Trop J Environ Sci)

e-ISSN: 2215-3896

(Julio-Diciembre, 2021) . Vol 55(2): 71-90

DOI: https://doi.org/10.15359/rca.55-2.4

Open Access: www.revistas.una.ac.cr/ambientales e-mail: revista.ambientales@una.ac.cr Espinoza-Cisneros E.

Esta investigación pretende servir de apoyo para los esfuerzos integrados de planificación a nivel regional y local en la cuenca del río Savegre, apoyando procesos llevados a cabo por instituciones estatales como el Ministerio de Ambiente y Energía (MINAE), la Comisión Nacional de Emergencias (CNE), las asociaciones de desarrollo integral, organizaciones de acueductos rurales, cooperativas y grupos locales y regionales de productores rurales. Por ejemplo, conocer percepciones sobre amenazas a la calidad del agua fluvial ayudaría en los procesos de priorización de acciones estratégicas de grupos locales como acueductos rurales, organizaciones turísticas y asociaciones de desarrollo comunitario, así como también en las redes de extensión rural que buscan promover prácticas productivas que minimicen impactos en ecosistemas vulnerables. En general, con este trabajo se busca promover estrategias de sostenibilidad diseñadas de manera participativa que logren optimizar sus paisajes productivos en el plano social y ecológico, especialmente en el contexto de la reciente designación de la cuenca en el 2017 como Reserva de la Biosfera de la UNESCO.

\section{Declaración de conflicto de intereses}

Las personas autoras declaran que han cumplido totalmente con todos los requisitos éticos y legales pertinentes, tanto durante el estudio como en la producción del manuscrito; que no hay conflictos de intereses de ningún tipo; que todas las fuentes financieras se mencionan completa y claramente en la sección de agradecimientos; y que están totalmente de acuerdo con la versión final editada del artículo.

\section{Agradecimientos}

El autor agradece a la Vicerrectoría de Investigación de la Universidad de Costa Rica (UCR) por el generoso financiamiento para este estudio, bajo el proyecto B6-355: "Análisis espacial de las relaciones entre valores y acciones de conservación del agua y el rol de factores externos en sistemas funcionalmente interdependientes: el caso de la cuenca del Savegre, Costa Rica". También, se agradece a la Dra. Isabel Avendaño Flores por el apoyo administrativo, al Dr. Alejandro Cascante Campos, por la asesoría estadística, y a los estudiantes Sara Blanco Ramírez y Jeffry Garro Fallas, por la asistencia con el trabajo de campo. Finalmente, se agradece a la Revista y las personas revisoras anónimas por sus aportes a la versión final del escrito.

\section{Referencias}

Acevedo, H., Bustamante, J., Paniagua, L., Chaves, R. (2002). Ecosistemas de la Cuenca Hidrográfica Del Río Savegre, Costa Rica. Editorial INBio.

Bremer, L. L., Farley, K. A., Lopez-Carr, D. (2014). What factors influence participation in payment for ecosystem services programs? An evaluation of Ecuador's SocioPáramo program. Land Use Policy, 36(enero), 122-133. https://doi.org/10.1016/j.landusepol.2013.08.002

\begin{tabular}{|c|c|c|}
\hline 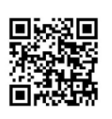 & (c) $\underset{\mathrm{BY}}{(\mathrm{NC}} \underset{\mathrm{SA}}{(0)}$ & 87 \\
\hline
\end{tabular}




\section{Revista de CIENCIAS AMBIENTALES Tropical Journal of Environmental Sciences}
Revista de Ciencias Ambientales (Trop J Environ Sci)
e-ISSN: 2215-3896
(Julio-Diciembre, 2021) . Vol 55(2): 71-90
DOI: https://doi.org/10.15359/rca.55-2.4
Open Access: www.revistas.una.ac.cr/ambientales e-mail: revista.ambientales@una.ac.cr Espinoza-Cisneros E.

Brody, S. D., Highfield, W., Alston, L. (2004). Does location matter? Measuring environmental perceptions of creeks in two San Antonio watersheds. Environment and Behavior, 36(2), 229-250. https://doi.org/10.1177/0013916503256900

Burton, R. (2004). Reconceptualising the "behavioural approach" in agricultural studies: A socio-psychological perspective. Journal of Rural Studies, 20(3), 359-371. https://doi.org/10.1016/j.jrurstud.2003.12.001

Burton, R., Wilson, G. (2006). Injecting social psychology theory into conceptualisations of agricultural agency: Towards a post-productivist farmer self-identity? Journal of Rural Studies, 22(1), 95-115. https://doi.org/10.1016/j.jrurstud.2005.07.004

Chan, K. M. A., Balvanera, P., Benessaiah, K., Chapman, M., Diaz, S., Gómez-Baggethun, E., Gould, R., Hannahs, N., Jax, K., Klain, S., y otros. (2016). Why protect nature? Rethinking values and the environment. Proceedings of the National Academy of Sciences, 113(6), 14621465. https://doi.org/10.1073/pnas.1525002113

Clark, C. F., Kotchen, M. J., Moore, M. R. (2003). Internal and external influences on pro-environmental behavior: Participation in a green electricity program. Journal of Environmental Psychology, 23(3), 237-246. https://doi.org/10.1016/S0272-4944(02)00105-6

Clayton, S., y Saunders, C. (2012). Introduction: Environmental and conservation psychology. En S. Clayton (Ed.), The Oxford Handbook of Environmental and Conservation Psychology (pp. 1-10). Oxford University Press. https://doi.org/10.1093/oxfordhb/9780199733026.001.0001

Espinoza-Cisneros, E. (2020). Influence of Context-Specific Cognitions and Values on Pro-Environmental Land Management in the Rio Savegre Watershed, Costa Rica. Journal of Latin American Geography, 19(4), 235-263. https://doi.org/10.1353/lag.2020.0086

Espinoza-Cisneros, E. (2018). Optimizing social-ecological analysis of coupled human-river systems through the integration of conceptual frameworks: The case of the Savegre watershed, Costa Rica. Revista Geográfica de América Central, 61E(3), 32-50. https://doi.org/10.15359/rgac.61-3.3

Fitzsimons, J. A., Wescott, G. (2007). Perceptions and attitudes of land managers in multi-tenure reserve networks and the implications for conservation. Journal of Environmental Management, 84(1), 38-48. https://doi.org/10.1016/j.jenvman.2006.05.009

Gifford, R., Nilsson, A. (2014). Personal and social factors that influence pro-environmental concern and behaviour: A review. International Journal of Psychology, 49(3), 141-157. https://doi.org/10.1002/ijop.12034

Hines, J. M., Hungerford, H. R., Tomera, A. N. (1987). Analysis and synthesis of research on responsible environmental behavior: A meta-analysis. The Journal of Environmental Education, 18(2), 1-8. https://doi.org/10.1080/00958964.1987.9943482

\begin{tabular}{|c|c|c|}
\hline 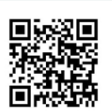 & (c) (1) (5) & 88 \\
\hline
\end{tabular}




\section{Revista de CIENCIAS AMBIENTALES Tropical Journal of Environmental Sciences}

$$
\begin{array}{r}
\text { Revista de Ciencias Ambientales (Trop J Environ Sci) } \\
\text { e-ISSN: 2215-3896 } \\
\text { (Julio-Diciembre, 2021). Vol 55(2): 71-90 } \\
\text { DOI: https://doi.org/10.15359/rca.55-2.4 } \\
\text { Open Access: www.revistas.una.ac.cr/ambientales } \\
\text { e-mail: revista.ambientales@una.ac.cr } \\
\text { Espinoza-Cisneros E. }
\end{array}
$$

Hukkinen, J. I. (2012). Fit in the Body: Matching Embodied Cognition with Social-Ecological Systems. Ecology and Society, 17(4). https://doi.org/10.5751/ES-05241-170430

Jacobs, S., Dendoncker, N., Martín-López, B., Barton, D. N., Gomez-Baggethun, E., Boeraeve, F., McGrath, F. L., Vierikko, K., Geneletti, D., Sevecke, K. J., y otros. (2016). A new valuation school: Integrating diverse values of nature in resource and land use decisions. Ecosystem Services, 22, 213-220. https://doi.org/10.1016/j.ecoser.2016.11.007

Jones, N., Shaw, S., Ross, H., Witt, K., Pinner, B. (2016). The study of human values in understanding and managing social-ecological systems. Ecology and Society, 21(1). https://doi. org/10.5751/ES-07977-210115

Kollmuss, A., Agyeman, J. (2002). Mind the Gap: Why do people act environmentally and what are the barriers to pro-environmental behavior? Environmental Education Research, 8(3), 239-260. https://doi.org/10.1080/13504620220145401

Larson, K. L., Santelmann, M. V. (2007). An Analysis of the Relationship between Residents' Proximity to Water and Attitudes about Resource Protection. The Professional Geographer, 59(3), 316-333. https://doi.org/10.1111/j.1467-9272.2007.00615.x

Mattey, J. (2014). El proyecto Desarrollo Sostenible de la Cuenca Hidrográfica del Rio Savegre, una experiencia de desarrollo rural territorial. Ministerio de Agricultura y Ganadería (MAG) Oficina Quepos, Costa Rica.

Meyfroidt, P. (2013). Environmental cognitions, land change, and social-ecological feedbacks: An overview. Journal of Land Use Science, 8(3), 341-367. https://doi. org/10.1080/1747423X.2012.667452

Ministerio de Ambiente y Energía y la Agencia Española de Cooperación Internacional [MINAE-AECI]. (2003). Plan de ordenamiento territorial de la cuenca hidrográfica del río Savegre [Documento técnico final]. San José, Costa Rica.

Naranjo, B. (2016). Ecología trófica de la trucha arcoíris Oncorhynchus mykiss (Salmonidae) en el Río Savegre, San Gerardo de Dota, Costa Rica. Tesis de licenciatura. Escuela de Biología Universidad de Costa Rica.

Nassauer, J. (1995). Culture and changing landscape structure. Landscape Ecology, 10(4), 229-

\begin{tabular}{|c|c|c|}
\hline 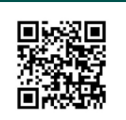 & (c) (i) (\$) & 89 \\
\hline
\end{tabular}
237. https://doi.org/10.1007/BF00129257

Price, J. C., Leviston, Z. (2014). Predicting pro-environmental agricultural practices: The social, psychological and contextual influences on land management. Journal of Rural Studies, 34, 65-78. https://doi.org/10.1016/j.jrurstud.2013.10.001

Prokopy, L. S., Floress, K., Arbuckle, J. G., Church, S. P., Eanes, F., Gao, Y., Gramig, B. M., Ranjan, P., Singh, A. S. (2019). Adoption of agricultural conservation practices in the United 


\section{Revista de CIENCIAS AMBIENTALES

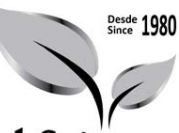 Tropical Journal of Environmental Sciences}

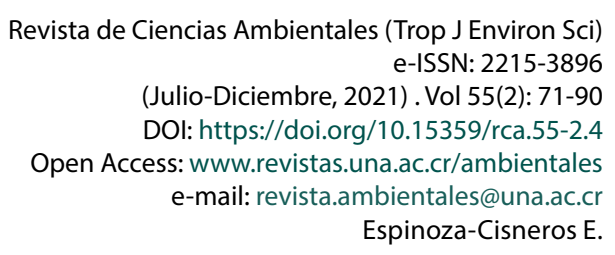

States: Evidence from 35 years of quantitative literature. Journal of Soil and Water Conservation, 74(5), 520-534. https://doi.org/10.2489/jswc.74.5.520

Rodríguez-Herrera, B. (2004). Distribución altitudinal, endemismo y conservación de mamíferos en la cuenca del río Savegre, Costa Rica. Brenesia, 61, 53-62.

Secretaría Ejecutiva de Planificación Sectorial Agropecuaria [SEPSA]. (2018). Situación de la afectación y daños causados por la Tormenta Nate al Sector Agropecuario y necesidades prioritarias (Decreto Ejecutivo N40677-MP). San José, Costa Rica.

Sistema Nacional De Áreas de Conservación [SINAC]. (2017). Sistematización Desarrollo Sostenible de la Cuenca Hidrográfica del Río Savegre. Ministerio de Ambiente y Energía. San José, Costa Rica.

Soule, M. J., Tegene, A., Wiebe, K. D. (2000). Land tenure and the adoption of conservation practices. American Journal of Agricultural Economics, 82(4), 993-1005. https://doi. org/10.1111/0002-9092.00097

Verdugo, V. C., Fonllem, C. T., Armenta, M. F., Sing, B. F., González, D. (2009). Orientación a la sostenibilidad como base para el comportamiento pro-social y pro-ecológico. Medio Ambiente y Comportamiento Humano: Revista Internacional de Psicología Ambiental, 10(3), 195-215.

\begin{tabular}{|c|c|c|c|c|c|}
\hline 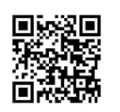 & (c) (1) & $\underset{\text { AMBENENALIES }}{\infty}$ & $\frac{1 \%}{\text { euna }}$ & 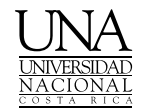 & 90 \\
\hline
\end{tabular}

